\title{
The sea urchin, a versatile model for eco-toxicity studies and ecological experimental research
}

\author{
D. Privitera*, M.G. Aluigi, C. Falugi, M. Chiantore \\ Dip.Te.Ris. University of Genoa, C.so Europa 26, 16132 Genova, Italy \\ *privitera.davi@gmail.com
}

KEYWORDS: Sea urchin, eco-toxicology, experimental ecology

\begin{abstract}
Echinoderm early developmental stages represent a good tool for toxicity testing in different fields, ranging from environment to food contamination, and in full respect of the $3 R$ s objectives (Reduction, Refinement, Replacement of animal experiments), that will lead to the reduction of vertebrate use for toxicity testing. Further, sea urchins are key species in a wide range of marine habitats, as they are able to structure algal community. Experiments and observations aiming at the characterization of anthropogenic or climate changes effect on their settlement, population structure, feeding behaviour and reproductive condition, may be useful to describe future scenarios regarding the whole marine community. The present paper represents a short review of the possible applications of eco-toxicity bioassays using Paracentrotus lividus gametes and embryos. Further, examples of ecological researches, involving sea urchins, aiming at the definition of future scenarios will be presented.
\end{abstract}

\section{Introduction}

Early developmental stages of echinoderms, in particular sea urchins, represent a convenient experimental model to investigate the mechanisms driving development and differentiation in higher organisms, including mammalians. This is supported by the fact that recently, the results of the project "Sea Urchin Genome", carried out by the California Institute of Technology, revealed a high degree of mammalianurchin homologies. Thus, sea urchin early development and differentiation has been proved to be a suitable alternative model for the analysis of risk represented by environmental pollutants on environmental and human health and food contamination [1-4]. Further, such a model fully respects the 3Rs objectives (Reduction, Refinement, Replacement of animal experiments) [i.e.5], that will eventually lead to the reduction of high vertebrate use for toxicity testing. Sea urchin is one of the few organismic models considered promising by the European Agency for Alternative models (ECVAM). Further, sea urchins role in marine ecology is particularly relevant. Several sea urchins species, for example Paracentrotus lividus and Arbacia lixula in the Mediterranean Sea [i.e. 6, 7], and Diadema antillarum in the Atlantic Ocean [8] are considered key species of photophilic assemblages. In fact, thanks to their grazing activity, whose power is strongly linked to population structure, they are able to handle the shift from photophilic algal communities to coralline algae dominated ones [i.e. 9]. In this way, the whole ecosystem functioning is potentially affected, the established trophic chains are altered and a wide range of marine organisms (i.e. fishes, corals) are affected, whose populations dynamics is linked to the structure of algal communities [7]. Thus, in order to describe theoretical future scenarios of marine ecosystems, related to the occurring global changes, marine ecologists often focus their attention on sea urchins response to potentially conditioning factors, such as sea water acidification and temperature increase [10] and interference of predator alien species or harmful micro and macro-algae, In this short review, we supply examples of toxicity tests, using the Mediterranean sea urchin P. lividus, related to different events and to different contaminants, including pesticides, nanoparticles and pre-chemical analysis of sediments. We will further describe how it has been possible to develop a theoretical future scenario of the Mediterranean sea in relation to global changes by experimentation regarding sea urchins population dynamics.

\section{Toxicity tests}

Sea urchin embryonic development has been studied since more than one century, and the complex nets of intercellular communications leading the different events is well known, as well the possibility for environmental molecules and their residuals to interfere with such communications, causing developmental anomalies. The good characteristics of the model are: ease of use, as the sea urchin fertilization occurs outside the maternal body; high number of gametes and embryos, allowing the statistical elaboration of the tests results; speed of responses, mainly for some tests such as the spermiotoxicity test; possibility of standardization intra- and inter-laboratory; cost-effectiveness; high throughput of results. The biomarkers allowed by this model are numerous, and easily quantifiable; e.g. the number of eggs fertilized by control 
and exposed sperms, the rate of cell proliferation during the first developmental phases, the number of anomalous larvae (generic toxicity tests) or more specific targets, such as the class of embryonic and larval anomalies [4], intracellular calcium release [11] transcription factors delivery to the nucleus [12].

These tests have been used to characterize the biological effects and targets of agricultural pesticides, such as carbamates and organophosphates [13]; in addition, a number of environmental emerging risks has been quantified and identified by use of the spermio- and embryo-toxicity test, such as cell proliferation enhancement caused by different types of electromagnetic fields $[14,15]$, radioactivity in suspect areas (unpublished data), metallic nanoparticles from combustion [16].

\section{Experimental ecology}

The population structure of sea urchins is conditioned by recruitment, strongly related to larval development, metamorphosis success and juvenile survival, and by adult fitness, primarily linked to food availability and presence of competitors. Thus experimental researches aiming at the characterization of stressors effects on sea urchins population dynamics have to focus on all their life stages, taking in account also inter and intra-specific interactions.

A. lixula and P. lividus role in barren grounds formation and maintenance has been deeply studied, both through experimental [17] and descriptive studies [18] and it has been suggested that the former species plays a more relevant role, potentially furthermore increased by the absence of $P$. lividus. In fact, this species grazing on photophilic algae is more competitive although the effect produced on algal communities seems to be less relevant than the coexisting species one. Further, A. lixula population fitness, in terms of gonadic production and size frequency distribution features, on barren habitat underlines that this species is better adapted to live on coralline algae dominated environments [6]. In lab experiments regarding temperature effect on larval development, and substrate selectivity for metamorphosis of the two species [19] further underlined A. lixula preference for high temperatures $\left(>22^{\circ} \mathrm{C}\right)$ and for calcareous or naked rocky substrates, while for $P$. lividus no substrate preference have been reported and lower temperatures $\left(<20^{\circ} \mathrm{C}\right)$ seem to favour larval growth and survival. Such findings, taking in account the increasing temperatures of the Mediterranean Sea, lead to hypothesize that $A$. lixula population are going to be increased while $P$. lividus ones may be reduced. Thus, it has been suggested the trigger of a feed-back loop in which barren areas will grow in number and in extension and $A$. lixula settlement will be facilitated.

\section{References}

[1] Buznikov GA, Nikitina LA, BezuglovV.V., Lauder J.M., Padilla S., Slotkin TA. 2001.An invertebrate model of the developmental neurotoxicity of insecticides: effects of chlorpyrifos and dieldrin in sea urchin embryos and larvae. Environ. Health Persp. 109(7):651-661.
[2] Falugi C.,Lammerding-Koppel M.rAluigi M.G. 2008. Sea urchin development:an alternative model for mechanistic understanding of neurodevelopment and neurotoxicity. Birth Defects Research. C. Embryo Today, 84(3): 188-203.

[3]Aluigi M.G.Angelini C., Corte G., Falugi C.2008.The sea urchin, Paracentrotus lividus, embryo as a "bioethical" model for neurodevelopmental toxicity testing. effects of diazinon on the intracellular distribution of OTX2-like proteins. Cell Biol.Toxicol., 24(6): 587-601

[4]Aluigi M.G., Falugi C., Mugno M.G.,Privitera D. Chiantore M. 2010. Dose-dependent effects of dhlorpyriphos, an organophosphate pesticide, on metamorphosis of the sea urchin, Paracentrotus lividus. Ecotoxicology, 19:520-529.

[5] Passantino A. 2008.Application of the 3Rs Principles for animals used for experiments at the beginning of the 21 st Century.Annu. Rev. Biomed. Sci., 10:27-32.

[6] Chiantore M.,Vielmini I., Privitera D., Mangialajo L, Cattaneo-Vietti R. 2008. Indirect human impact effects on the population structure of Paracentrotus lividus and Arbacia lixula. Chem. Ecol., 24: 145-147.

[7] Privitera D., Chiantore M., Mangialajo L, Glavic N., KozulV., CattaneoVietri R. 2008. Inter- and intra-specific competition between Paracentrous lividus and Arbacia lixula in resource-limited barren areas.J. Sea Res., 60:184-192.

[8] Carpenter R.C. 1981. Grazing by D. antillonum and its effect on the benthic algal community.j. Mar. Res., 39:749-765.

[9] Basket M.L,Solomon AK. 2010. Recruitment facilitation can drive alternative states on temperate reefs. Ecology, 91(6):1763-1773.

[10] Intergovernmental Panel on Climate Change (IPCC) 2007.IPCC Fourth Assessment Report-Climote Change 2007:The Physical Science Basis Summary for Policymakers.

[11] Harrison P.K., Falugi C.,Angelini C., Whitaker M.J.2002 Muscarinic signalling affects intracellular calcium concentration during the first cell cycle of sea urchin embryos. Cell Calcium, 31 (6):289-297.

[12] Aluigi M.G.,Angelini C., Corte G., Falugi C. 2008. The sea urchin, Paracentrotus lividus, embryo as a "bioechical" model for neurodevelopmental toxicity testing. effects of diazinon on the intracellular distribution of OTX2-like proteins. Cell Biol.Toxicol., 24(6): 587-601.

[13] Pesando D., Huitorel P., DolciniV.,Angelini C., Guidetti P., Falugi C. 2003. Biological targets of neurotoxic pesticides analysed by alteration of developmental events in the Mediterranean sea urchin, Paracentrotus Fividus. Mar. Environ. Res., 55(1):39-57.

[14] Falugi C., Grattarola M., Prestipino G.1987. Effects of low-intensity pulsed electromagnetic fields on the earty development of sea urchins. Biophys. J., 51(6): 999-1003.

[15] Ravera S., Falugi C., Cakia D., Pepe I.M., Panfoli I., Morelli A. 2006. First cell cycles of sea urchin Paracentrotus lividus are dramatically impaired by exposure to extremely low-frequency electromagnetic field. Biol. Reprod., 75(6): 948-953.

[16] Falugi C.,Aluigi M.G., Chiantore M.C., Privitera D., GattiA, Fabrizi A, PinsinoA. Matranga V. 2010. Uptake of metal nanoparticles in sea urchins: toxic effects on reproduction and immunity. The 4th Bilateral Seminar Italy-Japan (CNR-JSPS) Physical and Chemical Impacts on Marine Organisms: For Conservation of Biodiversity and Sustainabitity. Center for Academic and Culural Exchange - Aichi Prefectural Univ. Nagakute, Aichi,Japan, October 24-27, 2010,214-227.

[17] Bulleri F., Benedetti-Cecchi L, Cinelli F. 1999. Grazing by the sea urchin Arbacia lixulo (L) and Paracentrotus Ividus (Lam.) in the Northwest Mediterranean. J.Exp. Mar. Biol. Ecol, 241:81-95.

[18] Micheli F., Benedetti-Cecchi L, Gambaccini S., Bertocci I., Borsini C., Osio G.C., Romano F.2005.Alternate states, marine protected areas, and the structure of Mediterranean rocky-reef assemblages. Ecol. Monogr., 75:81-102

[19] Privitera D., Noli M., Falugi C. Chiantore M. 2010.Temperature and substrate effect on larval development and metamorphosis induction of the sea urchins A. lixula and P. lividus. Oral Communication. International meeting "Life In Warming Water" 47 October, Kiel. 